\title{
Memoria del horror: Las brutas, de Juan Radrigán; Hans Pozo, de Luis Barrales; e Hilda Peña, de Isidora Stevenson
}

\author{
Sara Rojo \\ Universidade Federal de Minas Gerais (UFMG) \\ y Conselho Nacional de Desenvolvimento \\ Científico e Tecnológico (CNPq), Brasil.
}

\section{Resumen}

Este trabajo se centrará en tres obras dramáticas chilenas: Las brutas (1980), de Juan Radrigán; Hans Pozo, de Luis Barrales; e Hilda Peña, de Isidora Stevenson. En las tres se retorna a hechos reales: El suicidio de tres mujeres de la etnia Colla, el descuartizamiento de Hans Pozo y el tiroteo tras el asalto al Banco O’Higgins perpetuado por el Movimiento Juvenil Lautaro. Estos hechos son teatralizados y, para ello, se recurre a la memoria colectiva, a la imaginación y a los contextos sociales de enunciación. Son relatos delirantes escritos en la variante popular de los personajes protagonistas, que transitan entre lo real y lo ficcional. El horror se instaura a partir del relato de la vivencia de esas tres mujeres colla, de las voces de los sujetos involucrados en la vida del descuartizado y de la voz de la madre de uno de los muertos en el tiroteo en Hilda Peña.

Palabras clave teatro chileno, hechos históricos, memoria, violencia, ficcionalización 
Abstract

Memories of horror: Las Brutas, by Juan

Radrigán, Hans Pozo, by Luis Barrales, and

Hilda Peña, by Isidora Stevenson.

This work will focus on three Chilean plays: Las brutas (1980), by Juan Radrigán, Hans Pozo, by Luis Barrales, and Hilda Peña, by Isidora Stevenson. All three of them return toreal events: the suicide of three women of the Kolla ethnic group, the dismemberment of Hans Pozo and the shooting after the assault on the O'Higgins Bank perpetuated by the Lautaro Youth Movement. These incidents are fictionalized and, for this, collective memory, imagination and social contexts of enunciation are used. They are delusional stories written in the popular variant of the main characters, who travel between the realand the fictional. The horror is established from the story of the experience of these three Kolla women, the voices of the individuals involved in the life of the dismembered man, and the voice of the mother of one of the dead men in the shooting in Hilda Peña.

Resumo

Memória do horror: Las brutas, de Juan Radrigán, Hans Pozo, de Luis Barrales, e Hilda Peña, de Isidora Stevenson

O trabalho focalizará em três obras dramáticas chilenas: Palavras-chave: teatro chileno, fatos históricos, memória, violência, ficçionalização

Las brutas (1980), de Juan Radrigán, Hans Pozo, de LuisBarrales, e Hilda Peña, de Isidora Stevenson. Nas três se retorna a fatos reais: $\mathrm{O}$ suicídio de três mulheres da etnia Colla, o esquartejamento de Hans Pozo e o tiroteio após o assalto ao Banco O'Higgins perpetuado pelo Movimento Juvenil Lautaro. Estes fatos são teatralizados e, para isso, se recorre à memória coletiva, à imaginação e aos contextos sociais de enunciação. São relatos delirantes escritos na variante popular das personagens protagonistas, que transitam entre o real

Keywords:

chilean theater, historical events, memory, violence, theatrical 
e o ficcional. O horror instaura-se a partir do relato da vivência dessas três mulheres colla, das vozes dos sujeitos envolvidos na vida do escuartejado e da voz da mãe de um dos mortos no tiroteio em Hilda Peña.

«Es sabido que no hay una memoria única, sino que distintos actores y distintas generaciones diferirán en el sentido que le dan al pasado. Para algunos hay también diversos pasados, cortos y acotados (regímenes dictatoriales establecidos con un calendario político centrado en los "acontecimientos"); procesos que se desarrollan en un tiempo más largo para otros. A su vez, el énfasis en el "pasado reciente" puede opacar violencias y discriminaciones en pasados anteriores o en condiciones estructurales.» (Jelin, Elizabeth. Memoria y democracia.

Una relación incierta)

En este trabajo continúo una línea presente, de manera periférica, en mi último libro Teatro latino-americano em diálogo: produçấo e visibilidade, publicado en 2016. En ese libro, analicé la pieza Escuela, del dramaturgo chileno Guillermo Calderón. Esa obra se construyó en torno a una de las grandes problemáticas de las últimas décadas, pero que es necesario analizarla en su relación con nuestro pasado: ¿la injusticia social justifica la violencia? la imagen, durante toda la obra, es limpia (sin recursos), se trata de personas en una escuela para aprender a implementar la lucha armada. Lo que importa es el debate que se expone con la teatrali- zación de esta formación clandestina de guerrilleros. Guillermo Calderón y un grupo de actores crearon ese espectáculo con apoyo de exmilitantes. Uno de ellos, Jorge Mateluna, después de estar I2 años preso por su participación en la guerrilla, fue nuevamente acusado y encarcelado ahora por su supuesta participación en un asalto a un banco. Este hecho generó una nueva obra que ha contribuido a darle fuerza al movimiento social por la libertad de Mateluna, marcando de qué forma la estética y la realidad se contaminan mutuamente.

Este no es el único caso aislado y para demostrarlo escogí tres obras de perío- 
dos entre la dictadura y la posdictadura chilenas. Mi hipótesis es que existe una contaminación entre ambos imaginarios, especialmente, con relación a los hechos relativos al autoritarismo y la violencia del período pinochetista y sus ecos posteriores. De hecho, podemos considerar esas producciones como movimientos que rescatan el pasado para entender la violencia del presente neoliberal. Esas propuestas utilizan lo real por medio de imágenes anacrónicas (Didi-Huberman, 20II) que se insertan en los códigos de la ficcionalidad, sin aspiraciones de veracidad strictu sensu.

La primera obra, Las Brutas, de Juan Radrigán (1937-2016), se estrenó en 1980 (dirección Arnaldo Berríos). Esta creación está basada en el suicidio, o asesinato por abandono, en el sector de La Tola, a 4000 metros de altura y a I9o kilómetros de la ciudad chilena de Copiapó (región de Atacama), de las tres hermanas Quispe Cardozo, de la etnia Colla, en 1974 (López Moya, en línea). Recordemos que el golpe militar fue en 1973 y que, por lo tanto, este hecho podría haber quedado diluido entre los innumerables casos de rupturas a los derechos humanos de ese período, si no fuese por un cierto carácter mítico que adquirió la imagen desolada de estas mujeres ahorcadas y colgadas de una piedra junto a sus animales.

Esa imagen va a ser el motor que permitirá que diversos creadores discutan la violencia y la invisibilidad de los indígenas en el pasado y en el presente chilenos. Recordemos, entre otras cosas, que la etnia Colla está en extinción. Las otras dos obras dramáticas son de dos escritores jóvenes: Hans Pozo, 2007, de Luis Barrales, dirigida por Isidora Stevenson, e Hilda Peña, de Isidora Stevenson, 20I4, dirigida por Aliocha de la Sotta. En ambas se retorna a hechos reales: el descuartizamiento de un joven periférico por un pequeño empresario con quien sostenía relaciones sexuales por dinero y el tiroteo - con las consecuentes ocho muertes- tras el asalto, de 1990, al Banco O'Higgins del Faro Apoquindo perpetuado por el Movimiento Juvenil Lautaro en "democracia». Estos hechos son teatralizados y, para ello, se recurre a la memoria colectiva, a la prensa, a la imaginación y a los contextos sociales de enunciación. No hay fronteras fijas entre esas instancias. Son relatos delirantes escritos en la variante popular de los personajes protagonistas, textos que transitan entre lo real y lo ficcional. El horror se instaura en Hans Pozo a partir de la narrativa del propio personaje y de aquellos que se relacionaron con él (la mujer, el asesino, la madre, el personaje-actor que lo encarna). En Hilda Peña, la única voz que escuchamos es la de la madre, quien nos relata su encuentro con un menor abandonado que adoptará, amará, verá morir sin entender el porqué de su muerte.

Las Brutas fue escrita al fin de la década de 1970 y estrenada en el Puerto de Val- 
paraíso por la compañía El Farol en i98o. Esta última década fue la de los movimientos sociales de resistencia con el objetivo de defender los derechos civiles perdidos. Según Gabriel Salazar (2002:242), entre I983 y 1987, ocurrieron 25 jornadas de protestas. Las movilizaciones servían para diversos fines: comprar en conjunto, proteger la salud de la colectividad, asumir la educación de forma comunitaria o denunciar la impunidad. En este período, la represión dictatorial obligó a desplazar los espacios propios del ejercicio político $y$, por ello, los palcos se transformaron en la voz de la disidencia. Juan Radrigán los utilizó de forma reiterada para exponer situaciones que estaban al margen del sistema y que, inclusive, dieron, con posterioridad, origen a otras creaciones. De hecho, lo sucedido con las hermanas Quispe y la obra de Radrigán fueron la base de varias construcciones artísticas: Las Hermanas Quispe, un documental, de Octavio Meneses (2008), una pieza de danza, La extintas, de Andrés Cárdenas y la Compañía de papel (20I4), y un film, Las niñas Quispe, de Sebastián Sepúlveda (20I4). El director de este film señala:

La dictadura impacta en el sentido de que hay una racionalización neoliberal en el mundo de la llanura, ellas son gente de las montańas, y el asunto es que hay un choque cultural, una incomprensión entre un mundo modernizador, racionalista y el mundo de una cultura ancestral que no entiende por qué se le niega su forma de ser. (Sepúlveda, en línea)

Es el período del terrorismo de Estado, en todas sus expresiones (torturas, desaparecimientos, centros de detención abiertos y secretos, campos de concentración, relegaciones, teléfonos grapados y exilios), Radrigán fue la voz que, siguiendo una tradición literaria importante en Chile, asumió como temática central a los sectores marginalizados. El diferencial es que esa tradición realiza este movimiento a partir de una enunciación de quien conoce de dentro ese espacio y lo representa sin idealizaciones ni abstracciones, inclusive con las contradicciones a la vista. Dentro de esa misma tradición, lo antecedieron Manuel Rojas y Antonio Acevedo Hernández.

La dramaturgia de Radrigán reproduce la sensación de impotencia del sujeto que muchas veces anula la capacidad de resistir. No podemos dejar de ver en sus textos el «síntoma» de una sociedad enferma ni el carácter estético de una «obra de pérdida» (Didi-Huberman, 20Io), de pérdida de democracia, de esperanza, de ser. El mecanismo utilizado es revelar, hacer resurgir lo oculto que la sociedad niega. Didi Huberman define el concepto de síntoma como:

Uma espécie de formação crítica que, por um lado, perturba o curso normal do rio (eis aí seu aspecto de catástrofe, no sentido 
morfológico do termo) e, por outro lado, faz ressurgir corpos esquecidos pelo rio ou pela geladeira mais acima, corpos que ela «restitui», faz aparecer, torna visíveis de repente, mas momentaneamente: eis aí seu aspecto de choque e de formação, seu poder de morfogênese e de "novidade» sempre inacabada, sempre, como diz tão bem Walter Benjamin. (20I0:I7I)

La duda de cómo fue la muerte de las hermanas Quispe Cardozo todavía conmueve a la sociedad chilena y la incerteza que existe sobre lo sucedido, es también la que recorre todas las otras muertes ocurridas en el período del terrorismo de estado. Las brutas responde a esa interrogante describiéndo la desesperación, la incomprensión de un poder sin nombre y la soledades lo que conducirá a las hermanas al suicidio. Radrigán fue hasta el lugar, lo recorrió y anotó datos sobre el paisaje, la lengua y las costumbres de los Colla (Escuela de espectadores, en línea).

Quizás el detonador del suicidio sea el hecho de que, en 1974, debe haber llegado hasta las hermanas la información de la existencia de un decreto que prohibía el corte de madera y la cría de caprinos pela desertificación que producían (López Moya, en línea). Radrigán a partir de la imagen de tres mujeres colgadas de una roca junto a sus animales se remontó a un ritual de suicidio existente en la comunidad Colla para crear Las brutas. Historia, mito y ficción se fundieron para potencializar el diálogo entre la realidad y la creación escénica. El hecho concreto es que un mito que aún perdura entre los collas y la potencia de un texto que asume el compromiso político que exige el contexto dictatorial son los pilares que generan el diálogo entre realidad y teatralidad. El dramaturgo recreó el lenguaje y la dureza de los tres cuerpos impotentes frente a la sólida intemperie. Están solas y ya son viejas. Las nuevas generaciones las abandonaron, la hija de una de ellas y un primo se fueron.

La acción dramática se estructura en torno al miedo incontrolable de no ser capaces de enfrentar en la vejez esas medidas oficiales que no entienden. Saben, porque le contaron a alguien, que cambió el gobierno y que los policías están matando a los animales. ¿Cómo se pueden defender frente a un poder ser nombre y sin dirección? Esta situación no es muy diferente en Brasil. Según los datos presentados, en 13/o7/2016, en O País:

Menosprezados, desassistidos, abandonados, o índice de suicídio entre os indígenas alcança proporçóes alarmantes. Dados recolhidos no Mapa da Violência do Ministério da Saúde expóem que enquanto a média do Brasil é de 5,3 suicídios por Ioo mil habitantes, a incidência entre os indígenas atinge uma média de nove suicídios para cada Ioo mil habitantes, podendo chegar, em alguns municípios da região Norte, a 30 suicídios por too mil habitantes. Um 
estudo da ONU afirma que o suicídio entre jovens indígenas ocorre em um contexto de discriminação, marginalização, colonização traumática e perda das formas tradicionais de vida, que forjam um sentimento de isolamento social. (El País, en línea)

El caso policial de Hans Hernán Pozo Vergara, además de la pieza que analizaremos que obtuvo el Premio Municipal de Santiago y del Consejo Nacional del Libro y la Lectura como la mejor obra literaria del 2007, tuvo otras versiones artísticas que destacamos: El pecado de El Rucio: Las claves del crimen de Hans Pozo, Daniel Halpern, (2007) y la obra de artes visuales Greatest Hits, de Felipe Santander (2009). Hans Pozo se encuadra en lo que teóricamente hoy entendemos como vida desechable. Abandonado por sus padres y rechazado por el medio es llevado a una existencia de resto en la cual las reglas son las propias de mercancía de bajo costo y los placeres, los permitidos por el sistema a los «parias», a los que tienen, en los términos de Agamben (20I0), una vida «indigna de ser vivida»:

aquel que foi banido, não é, na verdade simplesmente posto fora da lei e indiferente a esta, mas é abandonado por ela, ou seja, exposto e colocado em risco no limiar em que vida e direito, externo e interno, se confundem. Dele não é literalmente possível dizer que esteja fora ou dentro do ordenamento. (Agamben, 20I0:35)
Hans Pozo, como señalé, fue expulsado de su casa por su madre por ser rubio y luego de pasar por varios hogares, entró en el tráfico, vivió de calle, practicó el sexo comercializado y, finalmente, fue descuartizado por celos, por miedo de la extorsión, por vergüenza de asumir una relación homosexual. El punto es cómo, dentro de un régimen que entendemos como democrático, las vidas de algunos de los que deberían ser sus miembros no entran dentro del sistema de derecho.

En la obra, se retoma a Hans Pozo desde una memoria resignificada, de un lugar diferente de aquel en el cual lo situaron las imágenes y narrativas de la prensa, posibilita al espectador una reconstrucción del personaje desde el propio cuerpo ficcionalizado y de la imagen que los otros (también ficcionalizados), que convivieron con él, crearon. Cristián Opazo, específicamente refiriéndose al personaje-actor, lo plantea de la siguiente forma:

El personaje actor descubrirá que el cuerpo del flayte puede, también prodigarle placeres alucinógenos $\mathrm{y} / \mathrm{o}$ sexuales vedados por la ley de la polis. A la mañana siguiente, el placer/ olor flayte se difuminará, la ciudad permanecerá ajena y el personaje-actor culposo (repetirá): «no te acordís que tuvimos esta charla... Ahí tenís mil pesos...». (Opazo, 20II:88)

La pieza está estructurada como un simulacro de tragedia (con derecho a coro 
de las vecinas post mortem) y con intervenciones brechtianas (prólogo, epílogo y canciones que historizan el relato). Esta polifonía de voces y formas (cada escena es denominada round, con excepción del prólogo y el epílogo) reproducen el murmullo social que produjo el macabro asesinato, pero a su vez desconstruyen el imaginario del lumpen tatuado divulgado por la prensa. Las imágenes finales nos retornan un sujeto que no fue padre para su hija, pero sí futura animita para el pueblo que hoy le pide milagros como muestra la canción final: ${ }^{1}$

La hija: (...) y aunque no llevaba nunca carnet de identidad

el tenía un verdadero nombre

y a pesar de que todos ustedes lo conocieron como el cupido carneado

el era HP

y aunque todos ustedes se crean con mejor papi

el mío salió en los diarios y la tele

$y$ al primero de ustedes que me vuelva a llamar la hija del descuartizado

de puente alto

¡yo le rompo los labios, corazón y dientes, de un puro puńete en el hocico! (sic; Barrales, 20IO:296)
La Pérgola de las floristas

Canción: La madre: (...)

Corona de margaritas

$\mathrm{Y}$ de tantas otras flores

A los pies de tu animita

Yo la pongo con dolores. (297)

La tercera obra, Hilda Peña, de Isidora Stevenson, fue la ganadora en la XVI Muestra de dramaturgia Nacional de 2013 y fue estrenada en 20I4. La pieza está contextualizada en el asalto al banco O'Higgins de 1993 y en el posterior intercambio de disparos entre el Movimiento Juvenil Lautaro (autor del asalto) y la policía. El episodio dejó muertos y heridos que, a su vez, convocaron y siguen convocando una reflexión sobre la violencia. En esta pieza, esa reflexión se realiza filtrada por la mirada de una madre que pierde al hijo adoptivo en el enfrentamiento. Al hijo, que el descarte social, le otorgó.

Además de esta obra, hay un video de Rocío Hernández y una versión de la compañía Los Contadores Auditores con el mismo tema. La situación de la que parten todas las creaciones ficcionales (es bueno enfatizar esto) es un asalto, en democracia, realizado por el Movimiento Juvenil Lautaro (nombre del héroe de la resistencia

1 Es importante connotar que la Pérgola de las Flores es una institución que marca su aprobación o compasión por determinada trayectoria vital con el lanzamiento de flores y entonación de canciones, es el camino de los destacados al cementerio. Otro hecho importante es que las personas comunes le hicieron a Hans Pozo un santuario en el cual ponen flores y piden milagros. 
mapuche a los españoles), a un banco de uno de los barrios más ricos de Santiago. Jaime Pinos lo describe de esta manera:

Cinco militantes del Mapu-Lautaro asal$\tan$ un banco en Las Condes. Durante el asalto muere el guardia. Huyen en un taxi que deben abandonar y abordan una micro intercomunal 24. La micro es rápidamente cercada por la policía. Hay un primer tiroteo donde un suboficial de carabineros es herido de muerte. Los lautaristas lanzan las armas por la puerta y las ventanas. El chofer agita un pañuelo blanco en señal de rendición. Sin embargo, la policía reanuda el tiroteo sin discriminar entre asaltantes y pasajeros inocentes. La micro recibe 162 impactos de bala, según establecerá luego el proceso judicial. El resultado final son 8 muertos y I2 heridos, varios de ellos de gravedad. Un niño de $\mathrm{I} 3$ años se cuenta entre los heridos. (Pinos, en línea)

Isidora Stevenson, aunque parte también de un hecho histórico y se acerca al realismo reproduciendo las formas lingüísticas de las mujeres populares, direcciona su relato hacia el campo de la ficción del horror y crea un ritual de muerte que la protagonista sigue para mantener el contacto con su hijo después de muerto. Una mujer adopta, casi sin darse cuenta, un niño de la calle como su hijo. En un proceso paulatino, el adolescente va ocupando espacios materiales y de afecto dentro del hogar. Un día, como cualquier otro, Hilda Peña está haciendo almuerzo y descubre en la televisión que lo mataron. La pieza desde la descripción de quien no entiende lo que sucede, nos lleva a un ritual que consiste en ir al cementerio para ver el cuerpo todos los días, aunque para eso tenga que pagar a los cuidadores con sexo oral. Esta acción permite a la madre percibir la descomposición y grita por un curandero que lo vuelva a la vida:

La descomposición de un muerto tiene cuatro etapas:

Fresco-hinchado-putrefacto-seco.

(Silencio)

Los del cementerio no entienden.

Me dicen que soy rara.

Que esto no se hace.

Raros ellos que les gusta que se la chupe alguien que no conocen.

(

Trate por favor de ver si mi niño se le quita ese frío.

Ese color.

Trate de ver si mi niño despierta.

Por favor.

(Pausa)

No ve que después se va a podrir.

No va a poder hacerse nada después. (Stevenson:s/p) ${ }^{2}$

2 Agradezco a la autora permitirme tener acceso a la obra. 
Se coloca en esta obra, lado a lado, la impotencia vivida frente a la experiencia de la memoria política con la de la madre que pierde al hijo producto de acciones policiales que no comprende. El Movimiento Juvenil Lautaro contaba, entre sus militantes, con jóvenes de los sectores populares, que sentían una fuerte decepción con la vuelta a la democracia, pues para ellos era una nueva fase de lo mismo. Las condiciones de vida de estos sectores no cambiaron, la sociedad seguía vigilada y las expectativas de una sociedad más justa no estaban en el escenario político-social. Esto los hizo asumir posiciones radicales que culminaron en acciones armadas prácticamente suicidas. Una de ellas, el asalto al Banco O'Higgins (nombre del padre de la Patria), en el período navideńo de 1993 , es la que dio origen o fue el detonador de la creación de Hilda Peña. La respuesta policial, para Pedro Rosas (2004), estaba dentro de la estrategia de «Seguridad ciudadana» que el gobierno de democracia restringida (recordemos que Pinochet aún era senador vitalicio) defendía.

La protagonista va relatando la construcción subjetiva de la relación afectiva entre madre e hijo, algunas veces preguntándose que quien lo "parió», pero la mayor parte del tiempo aceptando lo que sucedió como algo natural: «Fue mi hijo. No sé si fui su madre. Nunca le pregunté»" (Stevenson:s/p). Esta manera de construir la relación rompe con el estereotipo de la maternidad como una esencia propia del género femenino. Punto que establece un hilo conductor con Hans Pozo. Obra en la cual observamos el proceso inverso: una madre biológica que rechaza a su hijo por ser blanco y no tener cara de indio y con Las brutas donde una madre (producto de una violación) no quiere saber de su hija porque se fue, en su corazón está muerta. La memoria de la maternidad como esencia del cuerpo femenino para estos personajes no existe, las relaciones afectivas entre el hijo y la madre son procesos de construcción de afectividad. Según Wladimir Safatle, las sociedades son, en su estructura básica, «circuitos de afectos» (2016:15) y la alternativa estaría en desarrollar el desamparo-amparo en el lugar del miedo. En esos circuitos, me parece, que los «desposeídos» tendrían alguna posibilidad de salvarse, aunque si la cadena se rompe no les queda nada y es, exactamente, eso lo que sucede con los personajes de Radrigán y Barrales. La madre de Stevenson, por el contrario, asumió el círculo y grita pidiendo socorro a un milagrero. Sólo, que para el público creer en esa alternativa es muy difícil. Aunque no podemos dejar de reconocer que la religiosidad popular transformó a Hans Pozo en una animita y que muchas personas creen en los curanderos.

En estas obras pareciera que se abandona el intento de autenticidad histórica por uno de constructividad de una alternativa al horror. En Las brutas recurriendo al mito colla; en Hans Pozo 
rescatando su imaginario del divulgado por la prensa e identificándose con los deseos que del joven cuerpo del flyte emanan (el personaje actor cumple esta función dentro de la obra) y en Hilda Peña invocando lo que está más allá de la razón: un curandero que vuelva a la vida al hijo perdido. Jelín afirma:

El pasado es un objeto de disputa, donde actores diversos expresan y silencian, resaltan y ocultan distintos elementos para la construcción de su propio relato. Lo que encontramos es una lucha por las memorias, lucha social y política en la que se dirimen cuestiones de poder institucional, simbólico y social. A su vez, los fenómenos de memoria se manifiestan en distintos planos de la vida social: el plano institucional, el cultural, el subjetivo. (Jelín, en línea)

El plano de la memoria invocado en estas obras es el subjetivo, aun cuando partan de hechos históricos que envolvieron a la sociedad chilena como un todo y tengan un valor simbólico que traspasa al sujeto en cuanto tal. La presencia de lo real, en cuanto hecho histórico, se contamina con la teatralidad, con las subjetividades en disputa (seres históricos, personajes, actores, etc.) y con el mito. Eso permite que, de alguna forma, estas producciones documenten tanto lo privado cuanto los procesos históricos. Tal vez esa sea la forma de alcanzar, socialmente, un público acostumbrado a asistir el drama de seres individuales sentado en una confortable poltrona. Esta última reflexión me recuerda la frase de Jameson: «a estética também tende a projetar meditaçóes simbólicas ou escamoteadas nos dilemas ou ideais, sociais ou políticos» (2013:59).

El arte nos lleva a espacios escamoteados por el discurso racional, espacios que poseen una presencia contundente el juego político-social de un país. Por ello, planteo que, en las obras comentadas, las imágenes proyectadas, aunque sean de individualidades remiten a dos momentos importantes de la sociedad chilena: el inicio de la dictadura y la vuelta protegida a la democracia y que también permiten ver las imágenes escamoteadas en los análisis macro históricos. Esas imágenes nos posibilitan traspasar la frontera de lo evidente. Quizás dentro de ese juego es donde cabe el ritual, tanto el propio de una comunidad como el creado para ese fin. 
Referencias bibliográficas

- AGAMBEN, G. (2010). Homo-Sacer. O poder soberano e a vida nua. Belo Horizonte: Humanitas/UFMG.

- ALARCÓN, R. http://radio.uchile.cl/2015/01/29/hilda-pena-elretorno-de-isidora-stevenson-a-la-simpleza-del-lenguaje/ (acesso 29/08/2017).

- ASMANN, A. (2011). Espaços de recordação. Formas e transformações da memória cultural. Trad. Paulo Soethe. Campinas: Editora Unicamp.

- BARRALES, L. (2010). Hans Pozo. En Hurtado, M.L. y Barría, M. (Orgs. y Eds.). Antología: Un siglo de dramaturgia chilena. IV. 1990-2009. Santiago: Secretaría Ejecutiva de la Comisión del Bicentenario de Chile.

- DIDI-HUBERMAN, G. (2010). O que vemos, o que nos olha. Trad. de Paulo Neves. São Paulo: Editora 34.

.__ (2011). Ante el tiempo. Trad. de Oscar Antonio Oviedo Funes. Buenos Aires: Adriana Hidalgo.

- EL PAíls. Os índios nossos mortos. Recuperado de: https://brasil.elpais.com/brasil/2016/07/13/actualidad/1468422915_764996.html (acceso 28/08/2017).

- ESCUELA DE ESPECTADORES. Recuperado de: http://ww2. educarchile.cl/Portal.Base/Web/verContenido.aspx?ID=209986 (acesso 29/08/2017).

- JAMESON, F. (2013). Brecht e a questão do método. Trad. Maria Silvia Betti. São Paulo: Cosac \&Naify.

- JELÍN, E. Memoria y democracia. Una relación incierta. Recuperado de: http://www.scielo.org.mx/scielo.php?script=sci_arttext\&pid=S0185-19182014000200010 (acceso 21/09/2017). - LÓPEZ MOYA, M. La terrible muerte de las hermanas Quispe. Recuperado de: https://www.revistatierracultah.cl/?p=6143 (acesso 28/08/2017).

- OPAZO, C. (2011). Pedagogías letales. 201. Ensayo sobre dramaturgias chilenas Del nuevo Milenio.Santiago: Pontificia Universidad Católica/Ed. Cuarto propio.

- PINOS, J. Las balas que tuvimos que tragar Presentación de "1993", novela gráfica de Christián Gutiérrez (Christiano) 
La Calabaza del Diablo, 2012. Recuperado de: http://letras. mysite.com/jpi130612.html (acesso 26/08/2017).

- RADRIGÁN, J. (1993). Las Brutas. En Teatro. 11 obras (pp. 27 a 91). Segunda edición. Santiago: Lom.

- ROSAS, P. (2004). Rebeldía, subversión y prisión política. Crimen y castigo en la transición chilena 1990-2004. Santiago: Lom.

- SAFATLE, W. (2016). O circuito dos afetos. Corpos políticos, desamparo e o fim do indivíduo. Belo Horizonte: Autêntica.

- SALAZAR, G. e PINTO, J. (2002). Historia contemporánea de Chile. V. 5. Santiago.

- SEPÚLVEDA, L. En Dentone, C. Las Niñas Quispe: La muerte como un rito. Recuperado de: http://radio.uchile.cl/2014/09/08/lasninas-quispe-la-muerte-como-un-rito/ (acesso 29/08/2017).

- SteVEnSON, I. Hilda Peña. En prensa. 